\title{
The Effects of Formaldehyde on Cytochrome P450 Isoform Activity in Rats
}

\author{
Min Xu, Huaqiao Tang, Qian Rong, Yuanli Zhang, Yinglun Li, Ling Zhao, \\ Gang Ye, Fei Shi, and Cheng Lv \\ College of Veterinary Medicine, Sichuan Agricultural University, Chengdu 611130, China \\ Correspondence should be addressed to Yinglun Li; liyinglun01@163.com
}

Received 30 August 2016; Revised 1 February 2017; Accepted 12 February 2017; Published 7 May 2017

Academic Editor: Blanca Laffon

Copyright (c) $2017 \mathrm{Min} \mathrm{Xu}$ et al. This is an open access article distributed under the Creative Commons Attribution License, which permits unrestricted use, distribution, and reproduction in any medium, provided the original work is properly cited.

\begin{abstract}
Formaldehyde (FA) is an occupational and indoor pollutant. Long-term exposure to FA can irritate the respiratory mucosa, with potential carcinogenic effects on the airways. The effects of acute FA poisoning on the activities of CYP450 isoforms CYP1A2, CYP2C11, CYP2E1, and CYP3A2 were assessed by determining changes in the pharmacokinetic parameters of the probe drugs phenacetin, tolbutamide, chlorzoxazone, and testosterone, respectively. Rats were randomly divided into three groups: control, low FA dose (exposure to $110 \mathrm{ppm}$ for $2 \mathrm{~h}$ for 3 days), and high FA dose (exposure to $220 \mathrm{ppm}$ for $2 \mathrm{~h}$ for 3 days). A mixture of the four probe drugs was injected into rats and blood samples were taken at a series of time points. Plasma concentrations of the probe drugs were measured by HPLC. The pharmacokinetic parameters $t_{1 / 2}, \mathrm{AUC}_{(0-t)}$, and $C_{\max }$ of tolbutamide, chlorzoxazone, and testosterone increased significantly in the high dose versus control group $(P<0.05)$, whereas the CL of chlorzoxazone and testosterone decreased significantly $(P<0.05)$. However, $t_{1 / 2}, \mathrm{AUC}_{(0-t)}$, and $C_{\max }$ of phenacetin decreased significantly $(P<0.05)$, whereas the CL of phenacetin increased significantly $(P<0.05)$ compared to controls. Thus, acute FA poisoning suppressed the activities of CYP2C11, CYP2E1, and CYP3A2 and induced the activity of CYP1A2 in rats. And the change of CYP450 activity caused by acute FA poisoning may be associated with FA potential carcinogenic effects on the airways.
\end{abstract}

\section{Introduction}

Formaldehyde (FA) is an occupational and indoor pollutant, with potential carcinogenic effects on the airways. The International Agency for Research on Cancer classified formaldehyde (FA) as a human carcinogen (Group 1) in 2004 [1]. FA is an occupational and indoor pollutant, which is widely employed in industries and also emitted from furniture, building materials, and chipboard [2]. Industrial applications range from resins and adhesives for wood-based materials and fiber insulation, to textiles, biocides, paper adhesives, timber covers, plastic, leather, building materials, and even cosmetics [3-5]. Residual FA can be found in leather, flooring, and new cars. Although the release of FA from these materials has been significantly reduced by manufacturers in recent years, indoor concentrations in prefabricated houses have not decreased by the same amount [6-9]. In fact, FA has long been a topic of environmental policy discussions as an air-polluting substance which enters the body primarily through respiration.

FA is not only a potent trigger of inflammation in the lower respiratory tract but also has a negative effect on other organs [10]. It is generally accepted that FA acts mainly at the site of first contact; however, it also affects metabolism in many different organs and presents in every cell of the human body [11]. Research has shown that animals inhaling FA exhibit increases in reactive oxygen species (ROS), malondialdehyde (MDA), and DNA-protein cross-linking and decreased levels of glutathione (GSH) in the lungs and systemically $[12,13]$. FA mediated elevation in ROS and associated genotoxicity are implicated in the development of leukemia [14]. Other studies have shown that FA exposure is associated with elevated ROS/reactive nitrogen species (RNS) levels in the lungs as well as alterations in antioxidant enzyme concentrations [10]. After the oxidative damage caused by lipid peroxidation and protein biotransformation presented 
by individuals exposed to FA, there was recruitment of inflammatory cells [15]. In addition to the lungs, FA induced oxidative stress in the uterus and spleen [16-18]. Repeated treatments with $50 \mu \mathrm{M}$ FA changed the expression of more than 100 liver genes, showing that repeated inhalation of FA has widespread effects on major organs [19]. FA is metabolized to methanol and formic acid in the liver and erythrocytes after ingestion [20]. Current research on the toxicity of FA has in-depth damage in the liver, and FA induced liver injury model of research in recent years is also very mature [21, 22]. Such that Bakar et al. [23] found that FA markedly increased cell apoptosis in the liver.

The cytochrome P450 (CYP) enzyme system involved in metabolizing drugs in humans is predominantly expressed in the liver and intestine. Among the various CYP isozymes, CYP1A2, CYP2C9, CYP2C19, CYP2D6, and CYP3A4 are considered the most important metabolism enzymes [2426]. The expression and activity of CYPs can be induced or suppressed by exogenous and endogenous materials; reactive oxygen intermediates produced in vivo and in vitro have been implicated in the cascade of events, leading to a loss of CYP during inflammation [27, 28]. As part of the vaccine manufacturing process, some residual FA $(<0.02 \%)$ can be left behind, resulting in varying antibody responses to it $[29,30]$. Environmental and occupational exposure, principally via inhalation, is a continuous focus in FA risk assessments. Because the toxic effect of FA can be found in several organs, including the liver, we speculated that liver CYPs might be altered by expose to FA.

\section{Materials and Methods}

2.1. Chemicals and Reagents. FA (>99.0\%) was purchased from QILU SYNVA Pharmaceutical (Shandong, China). Phenacetin (>98.0\%), tolbutamide (>99.0\%), chlorzoxazone $(>99.0 \%)$, testosterone $(>98.0 \%)$, and the internal standard tinidazole (IS) $(>99.0 \%)$ were purchased from Dalian Mellon Biological Technology (Dalian, China). Highperformance liquid chromatography (HPLC) grade acetonitrile and methanol were purchased from Thermo Fisher Scientific (USA). Analytical-grade ethanol was purchased from Chengdu Kelong Chemical Reagent Factory (Chengdu, China).

2.2. Animals and Treatments. Twenty-four Sprague Dawley (SD) rats $(220 \pm 20 \mathrm{~g}$, male) were obtained from Chengdu Dossy biological technology (Chengdu, China). Prior to the experiments, all animals were acclimatized for 7 days in a ventilated room, which was maintained at $25 \pm 2^{\circ} \mathrm{C}$ and $70 \pm 10 \%$ relative humidity with a 12 -hour light/dark cycle. Thereafter, the rats were equally divided into three groups: control group, low-dose acute FA poisoning group, and high dose acute FA poisoning group. The rats were placed in a triad infected ark with a FA detector, and various concentrations of FA gas were passed through to create a model of acute FA poisoning. The high dose acute FA poisoning group was exposed to $220 \mathrm{ppm}$ FA for 2 hours for 3 days; the low-dose group was exposed to 110 ppm FA for 2 hours for 3 days. Control animals were maintained under similar conditions, but without FA exposure. Rats were allowed to eat and drink ad libitum except during the $2 \mathrm{~h}$ exposure period. All animal experiments were performed in compliance with the Animal and Ethics Review Committee of Sichuan Agricultural University.

After FA treatment, a cocktail solution of the different probe drugs $(50 \mathrm{mg} / \mathrm{mL}$ phenacetin, $25 \mathrm{mg} / \mathrm{mL}$ tolbutamide, $50 \mathrm{mg} / \mathrm{mL}$ chlorzoxazone, and $50 \mathrm{mg} / \mathrm{mL}$ testosterone in $45 \%$ ethanol-saline solution) was injected intraperitoneally to all rats at a dose of $1.0 \mathrm{~mL} / \mathrm{kg}$. Blood samples were collected at time points of 10,20,30,40,60,120,180, 240,300, and $360 \mathrm{~min}$ through the fundus venous and immediately centrifuged at $6000 \times \mathrm{g}$ for $10 \mathrm{~min}$ to obtain plasma. Then, $50 \mu \mathrm{L}$ plasma from each sample was stored frozen at $-80^{\circ} \mathrm{C}$ until further analysis.

2.3. Sample Preparation for HPLC Analysis. To each $50 \mu \mathrm{L}$ plasma sample, $150 \mu \mathrm{L}$ tinidazole $(100 \mathrm{mg} / \mathrm{mL}$ in acetonitrile) was added as the IS (standard tinidazole), vortexed for $1 \mathrm{~min}$ to mix. The samples were centrifuged at $8000 \times \mathrm{g}$ for $10 \mathrm{~min}$ to obtain the supernatant $(10 \mu \mathrm{L})$, which were injected into the HPLC system for analysis.

2.4. Chromatographic Apparatus and Conditions. A 1260 Series liquid chromatograph (Agilent Technologies, Waldbronn, Germany), equipped with a quaternary pump, degasser, autosampler, thermostat controlled column compartment, and Agilent 1260 infinity variable wavelength detector was utilized for the analysis. The instrument was controlled by ChemStation software (Agilent Technologies, Santa Clara, CA). Chromatographic separation was achieved on a Zorbax SB-C18 column (Agilent Technologies, Germany) $(4.6 \times 250 \mathrm{~mm}, 5 \mu \mathrm{m})$ with the column temperature set at $30^{\circ} \mathrm{C}$. The mobile phase consisted of acetonitrile (A) and $0.01 \mathrm{M}$ ammonium acetate in water $(\mathrm{B})$. The gradient elution was $30-50 \%$ A over $0-15 \mathrm{~min}$, holding at $50 \% \mathrm{~A}$ from $15-18 \mathrm{~min}$ and $50-30 \%$ A over $18-25 \mathrm{~min}$. The flow rate, injection volume, and UV-detection wavelength were $1.0 \mathrm{~mL} / \mathrm{min}, 10 \mu \mathrm{L}$, and $230 \mathrm{~nm}$, respectively. Quantification was performed by the peak-area method [31].

2.5. Statistical Analysis. The concentration-time profile of each probe drug was analyzed by DAS 2.0 (Wenzhou Medical College, Zhejiang, China). T-test was applied for statistical analyses using SPSS 19.0. A value of $P<0.05$ or $P<0.01$ was considered to be statistically significant. All analyses were repeated at least three times.

\section{Results}

3.1. Method Validation. To confirm the specificity and effectiveness of our HPLC analytical method, blank plasma was tested under the experimental conditions. There was no visible interference peak from the endogenous substances at the retention times for either IS or the probe drugs in the blank (Figure 1(a)) and sample plasma (Figure 1(b)). The retention times for IS, phenacetin, tolbutamide, chlorzoxazone, and testosterone were 5.28, 8.50, 6.70, 11.03, and $17.66 \mathrm{~min}$, respectively (Figure $1(\mathrm{~b})$ ). To quantify the probe 
TABLE 1: Linear calibration parameters and detected concentration ranges of the probe drugs.

\begin{tabular}{lccc}
\hline Analyte & Regression equation & $R^{2}$ & Concentration range $(\mu \mathrm{g} / \mathrm{mL})$ \\
\hline Phenacetin & $y=176.97 x+1.0617$ & 0.9968 & $0.25-250$ \\
Tolbutamide & $y=166.99 x+1.2795$ & 0.9992 & $0.25-250$ \\
Chlorzoxazone & $y=128.95 x+1.3377$ & 0.9996 & $0.25-250$ \\
Testosterone & $y=212.17 x+50.196$ & 0.9985 & $0.25-250$ \\
\hline
\end{tabular}

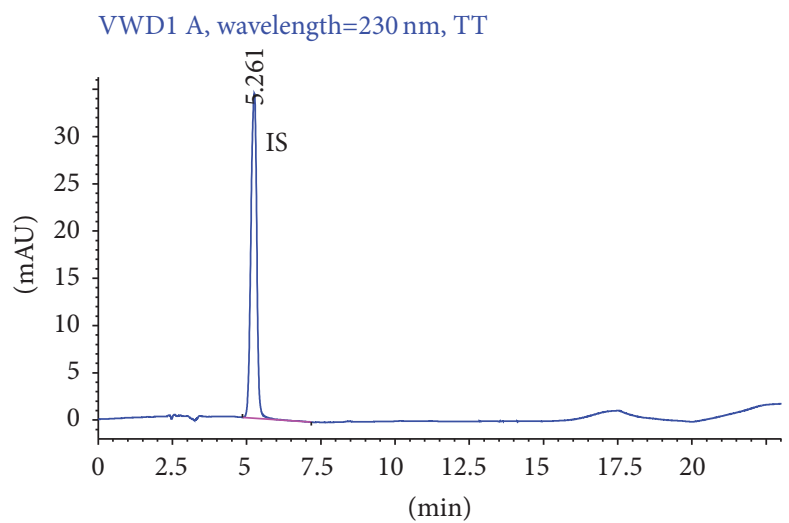

(a)

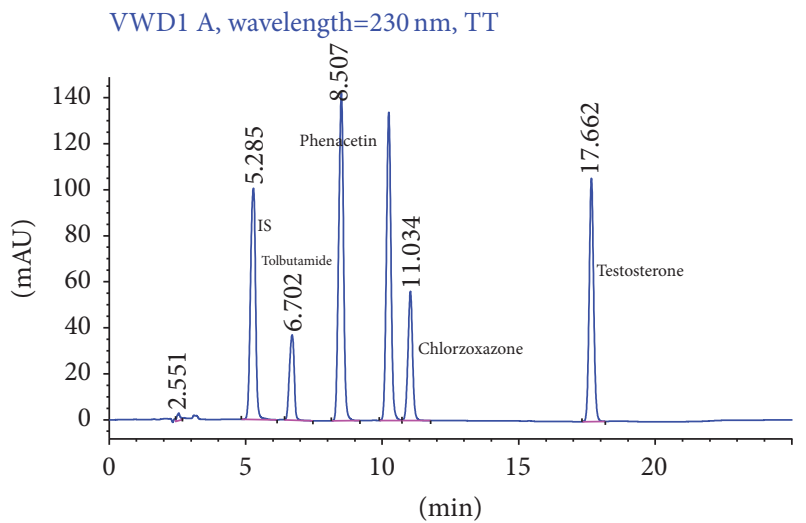

(b)

FIGURE 1: HPLC chromatogram of internal standard (IS) in the blank plasma and standard curves of the four probe drugs and IS added to the blank plasma.

drug concentrations in the sample plasma, the ratio of drug peak area to IS was used. The calibration curves were linear in the determined concentration ranges (Table 1).

3.2. Effect of FA on CYP1A2 Activity. Pharmacokinetic profiles of phenacetin in rats after FA treatment were used to describe the activity of CYP1A2. The effects of the different dosages of FA are presented in Table 2. Mean plasma concentration-time curves of phenacetin at different FA dosages are presented in Figure 2. After treatment with FA, $t_{1 / 2}, V_{d}$, and $\mathrm{AUC}_{(0-t)}$ of phenacetin decreased significantly compared to the control group; $C_{\max }$ of phenacetin decreased significantly only for high dose; however, CL increased significantly $(P<0.05$; Table 2$)$. In addition, the changes were dose-dependent. The results indicate that phenacetin metabolism in the treatment groups increases, and FA therefore has the potential to induce hepatic CYP1A2 activity in vivo.

3.3. Effect of FA on CYP2C11 Activity. CYP2C11 activity was evaluated by the comparing pharmacokinetic behaviors of tolbutamide in the control and different FA treatment groups. Listed in Table 2 are the main pharmacokinetic parameters of tolbutamide. Mean plasma concentration-time curves of tolbutamide in different groups are presented in Figure 3. After treatment with FA, $t_{1 / 2}$ of tolbutamide increased nonsignificantly $(P>0.05)$, whereas $V_{d}, \mathrm{AUC}_{(0-t)}$, and $C_{\max }$ of tolbutamide increased significantly compared to control group $(P<0.05)$; the $\mathrm{CL}$ of tolbutamide did not change. These results demonstrate significant inhibition of CYP2C11 activity by FA in rats.

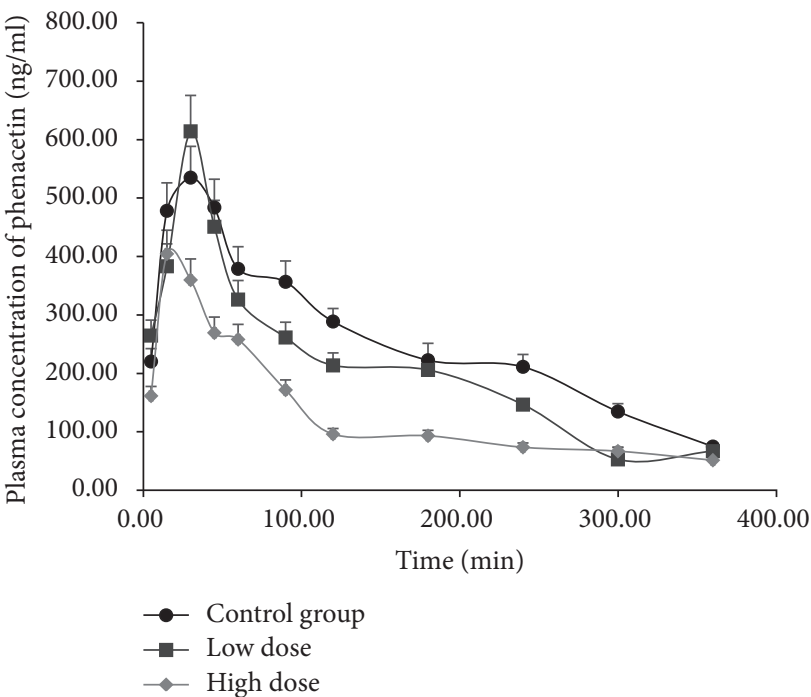

FIGURE 2: Mean plasma concentration-time curves of phenacetin in rats exposed to low or high dose of formaldehyde (FA).

3.4. Effect of FA on CYP2E1 Activity. The effects of different FA treatments on the pharmacokinetic parameters of chlorzoxazone in rats are presented in Table 2. Mean plasma concentration-time curves of chlorzoxazone in the different groups are presented in Figure 4. Compared to the control group, the pharmacokinetic parameters $t_{1 / 2}, V_{d}$, $\mathrm{AUC}_{(0-t)}$, and $C_{\max }$ of chlorzoxazone increased significantly after treatment with a high dose of FA; only CL decreased 
TABLE 2: Main pharmacokinetic parameters of probe drugs in rats treated with formaldehyde (FA) $(n=8$ per group, mean \pm SD).

\begin{tabular}{|c|c|c|c|c|}
\hline Probe drug name & Parameter & Control group & Low dose FA & High dose FA \\
\hline \multirow{5}{*}{ Phenacetin } & $t_{1 / 2}(\min )$ & $163.89 \pm 12.32$ & $110.24 \pm 13.19^{* *}$ & $92.42 \pm 8.34^{* *}$ \\
\hline & $\mathrm{CL}(\mathrm{L} / \mathrm{h} / \mathrm{kg})$ & $0.44 \pm 0.11$ & $0.61 \pm 0.13^{*}$ & $0.85 \pm 0.09^{* *}$ \\
\hline & $V_{d}(\mathrm{~L} / \mathrm{kg})$ & $105.07 \pm 9.78$ & $96.51 \pm 8.90$ & $81.5 \pm 7.89^{*}$ \\
\hline & $\operatorname{AUC}_{(0-t)}(\mathrm{mg} / \mathrm{mL} * \min )$ & $87.86 \pm 8.56$ & $71.7 \pm 7.65^{*}$ & $42.98 \pm 6.09^{* *}$ \\
\hline & $C_{\max }(\mathrm{mg} / \mathrm{L})$ & $543.90 \pm 35.06$ & $614.13 \pm 50.69^{*}$ & $359.81 \pm 31.24^{* *}$ \\
\hline \multirow{5}{*}{ Tolbutamide } & $t_{1 / 2}(\min )$ & $176.53 \pm 16.76$ & $181.24 \pm 18.67$ & $197.51 \pm 16.45$ \\
\hline & $\mathrm{CL}(\mathrm{L} / \mathrm{h} / \mathrm{kg})$ & $0.01 \pm 0.003$ & $0.01 \pm 0.002$ & $0.01 \pm 0.003$ \\
\hline & $V_{d}(\mathrm{~L} / \mathrm{kg})$ & $9.09 \pm 1.62$ & $10.10 \pm 1.31$ & $13.98 \pm 1.33^{* *}$ \\
\hline & $\mathrm{AUC}_{(0-t)}(\mathrm{mg} / \mathrm{mL} * \mathrm{~min})$ & $1481.73 \pm 177.98$ & $1592.93 \pm 182.08$ & $1660.67 \pm 117.98^{*}$ \\
\hline & $C_{\max }(\mathrm{mg} / \mathrm{L})$ & $6740.54 \pm 289.07$ & $7001.56 \pm 302.01$ & $7469.93 \pm 346.78^{*}$ \\
\hline \multirow{5}{*}{ Chlorzoxazone } & $t_{1 / 2}(\min )$ & $124.93 \pm 16.43$ & $133.92 \pm 11.53$ & $151.03 \pm 11.90^{* *}$ \\
\hline & CL (L/h/kg) & $0.23 \pm 0.04$ & $0.20 \pm 0.05$ & $0.16 \pm 0.03^{*}$ \\
\hline & $V_{d}(\mathrm{~L} / \mathrm{kg})$ & $41.16 \pm 2.34$ & $50.58 \pm 3.55^{* *}$ & $57.32 \pm 3.13^{* *}$ \\
\hline & $\operatorname{AUC}_{(0-t)}(\mathrm{mg} / \mathrm{mL} * \min )$ & $186.9 \pm 12.34$ & $216.75 \pm 18.78^{*}$ & $261.21 \pm 21.33^{* *}$ \\
\hline & $C_{\max }(\mathrm{mg} / \mathrm{L})$ & $1063.40 \pm 122.30$ & $1167.62 \pm 119.87$ & $1381.03 \pm 130.52^{*}$ \\
\hline \multirow{5}{*}{ Testosterone } & $t_{1 / 2}(\min )$ & $80.27 \pm 8.45$ & $89.73 \pm 10.09$ & $92.91 \pm 9.98^{*}$ \\
\hline & CL (L/h/kg) & $1.16 \pm 0.12$ & $1.11 \pm 0.21$ & $0.87 \pm 0.18^{*}$ \\
\hline & $V_{d}(\mathrm{~L} / \mathrm{kg})$ & $218.66 \pm 18.76$ & $213.40 \pm 13.32$ & $209.68 \pm 12.78$ \\
\hline & $\operatorname{AUC}_{(0-t)}(\mathrm{mg} / \mathrm{mL} * \min )$ & $37.85 \pm 4.32$ & $42.20 \pm 3.22$ & $52.91 \pm 2.76^{* *}$ \\
\hline & $C_{\max }(\mathrm{mg} / \mathrm{L})$ & $391.24 \pm 21.17$ & $423.92 \pm 26.74$ & $465.39 \pm 30.49^{*}$ \\
\hline
\end{tabular}

${ }^{*}$ Significantly different from control, $P<0.05$

${ }^{*}$ S Significantly different from control, $P<0.01$.

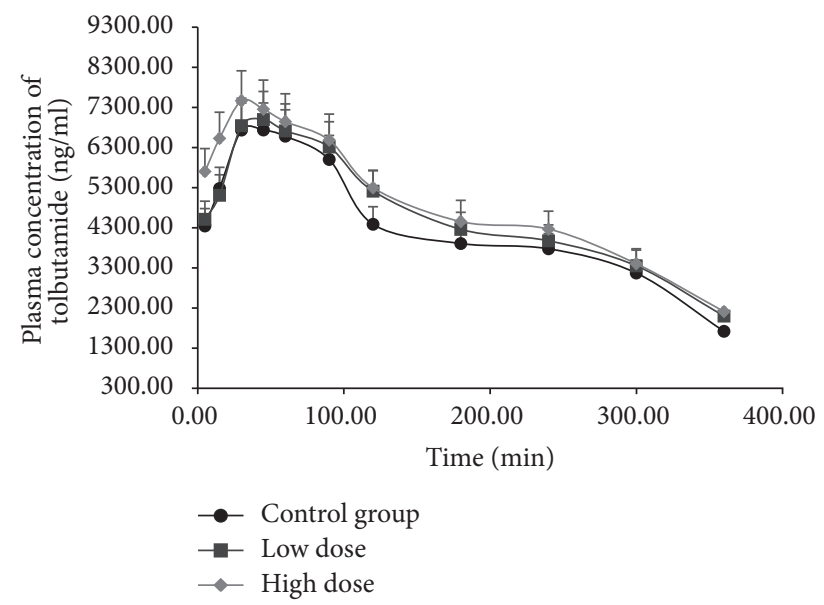

FIGURE 3: Mean plasma concentration-time curves of tolbutamide in rats exposed to low or high dose of formaldehyde (FA).

significantly $(P<0.05)$ with a high dose of FA. Therefore, the pharmacokinetic behaviors of chlorzoxazone indicate that FA inhibits rat hepatic CYP2E1 activity in vivo.

3.5. Effect of FA on CYP3A2 Activity. CYP3A2 activity was evaluated by comparing pharmacokinetic behaviors of testosterone between the control group and different FA treatment groups (Table 2). Mean plasma concentration-time curves of testosterone in the different groups are presented in Figure 5. After FA treatment, the pharmacokinetic parameters $t_{1 / 2}$,

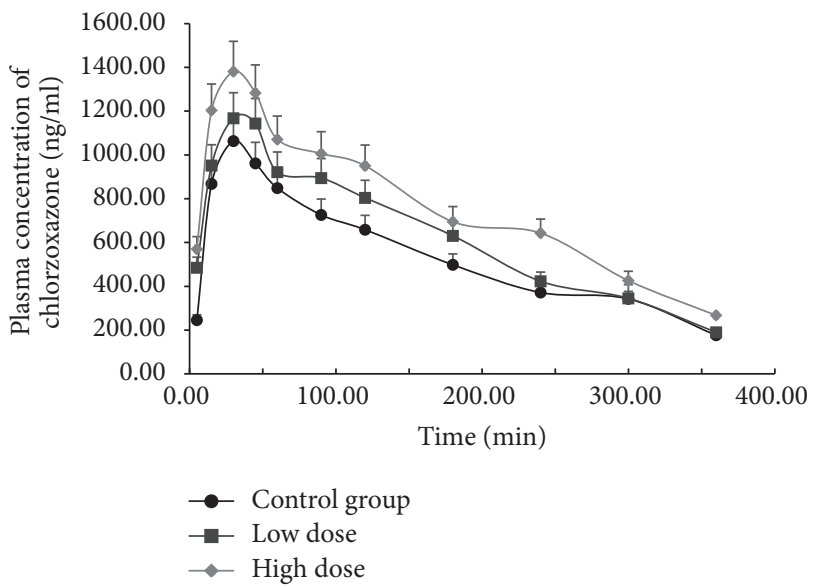

FIgURE 4: Mean plasma concentration-time curves of chlorzoxazone in rats exposed to low or high dose of formaldehyde (FA).

$\mathrm{AUC}_{(0-t)}$, and $C_{\text {max }}$ of testosterone in rats increased significantly in the high dose group compared to the controls, whereas CL of testosterone decreased significantly $(P<$ 0.05); $V_{d}$ decreased as well, albeit not significantly. The results indicate that a high dose of FA has the potential to inhibit rat hepatic CYP3A2 activity in vivo.

\section{Discussion}

FA is a ubiquitous occupational pollutant that is widely used in a variety of industries [32], as well as an indoor 


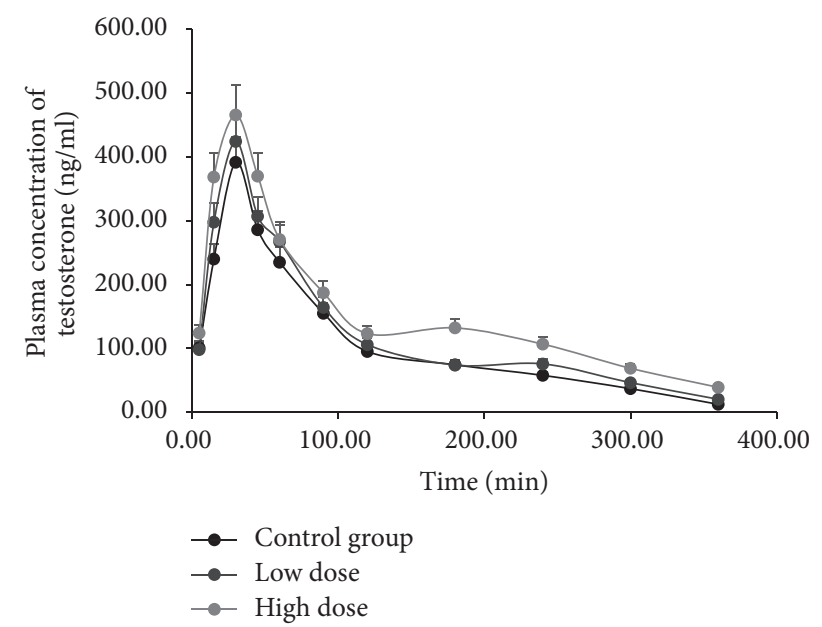

FIgURE 5: Mean plasma concentration-time curves of testosterone in rats exposed to low or high dose of formaldehyde (FA).

air pollutant [2]. Cardiovascular diseases, chronic respiratory disease, cancer, and hypertension are the main chronic, noncommunicable diseases in China [33]. These patients usually require long-term treatment, and they frequently come into contact with the widely distributed FA. If casual inhalation of FA can disrupt CYPs, FA may induce systematic oxidative stress and inflammation.

Sulfur dioxide $\left(\mathrm{SO}_{2}\right)$ can cause toxicological damage to multiple organs in animals. The systemic oxidative damage produced by $\mathrm{SO}_{2}$ inhalation may influence or promote the progression or occurrence of disease states in various organs, and not only the respiratory system [34-37]. Furthermore, $\mathrm{SO}_{2}$ exposure can inhibit the activities and mRNA levels of CYP2B1/2, CYP2E1, and CYP1A1/2 in lungs and livers of rats $[38,39]$. Studies have shown that hydrogen sulfide $\left(\mathrm{H}_{2} \mathrm{~S}\right)$ toxicity is dependent on ROS production [40], and $\mathrm{H}_{2} \mathrm{~S}$ exposure may inhibit the activities of CYP2B6, CYP2D6, CYP1A2, and CYP2C9 in rats [41]. At present, FA is widely used in various fields, and its toxic effects are of great concern. Like $\mathrm{H}_{2} \mathrm{~S}, \mathrm{SO}_{2}$ and other toxic gases, FA also affects CYPs. The results of this experiment show that FA exposure may inhibit the activities of CYP2E1, CYP2C11, and CYP3A2 and induce the activity of CYP1A2 in rats.

Compared to the control group, in the acute FA poisoning groups, $t_{1 / 2}, V_{d}, \mathrm{AUC}_{(0-t)}$, and $C_{\max }$ of phenacetin decreased significantly, but CL increased significantly $(P<0.05) . V_{d}$, AUC $_{(0-t)}$, and $C_{\text {max }}$ of tolbutamide increased significantly compared to the control group $(P<0.05) . t_{1 / 2}, V_{d}, \mathrm{AUC}_{(0-t)}$, and $C_{\max }$ of chlorzoxazone increased $(P<0.01)$ after treatment with FA, whereas CL decreased significantly $(P<$ 0.05). $t_{1 / 2}, \mathrm{AUC}_{(0-t)}$, and $C_{\max }$ of testosterone increased significantly in high dose FA groups compared to controls $(P<0.05)$; CL of testosterone decreased significantly in the high dose group $(P<0.05)$, and $V_{d}$ decreased as well, albeit not significantly $(P>0.05)$.

These results are important in terms of the effect of inhaling high amounts of FA on drug metabolism. After acute FA poisoning, drugs that are metabolized by CYP1A2,
CYP2C11, CYP2E1, and CYP3A2 are likely to show interactions. Therefore, we should pay close attention to changes in their plasma concentrations. FA is a reducing agent, it is speculated that oxidative damage may be an important molecular mechanism of the toxic effect of FA, or maybe like $\mathrm{H}_{2} \mathrm{~S}$ and $\mathrm{SO}_{2}$, it is caused a specific subtype gene expression changes and then changed the activity of particular subtype. The correlation research indicated $[42,43]$ that when exogenous substances cause CYP450 activity to change, it will cause activation of xenobiotic metabolism by cytochrome P450, production of oxidative stress, Nrf-2-mediated oxidative stress response, and oxidative DNA damage, subsequently, these may promote the development of cancer. Therefore, we hypothesized that the changes of CYP450 activity caused by acute FA poisoning may be associated with FA potential carcinogenic effects on the airways. Of course, this requires further testing to prove.

\section{Conclusions}

The concentrations of four probe drugs in rats plasma were successfully measured. In the experiment for acute FA poisoning and control group, there was a statistically significant increase in $\mathrm{AUC}_{(0-t)}, t_{1 / 2}$, and $C_{\max }$ for tolbutamide, chlorzoxazone, and testosterone in $\mathrm{FA}$ groups while $\mathrm{AUC}_{(0-t)}, t_{1 / 2}$, and $C_{\max }$ of phenacetin decreased significantly compared to the control group. In this experiment, we found that the activities of CYP2C11, CYP2E1, and CYP3A2 are inhibited, whereas that of CYP1A2 is induced following acute FA poisoning in rats. The results may make us pay close attention to the clinical oral use of drugs for the people after acute FA poisoning, and we speculate that the change of CYP450 activity caused by acute FA poisoning may be associated with FA potential carcinogenic effects on the airways.

\section{Conflicts of Interest}

The authors declare that there are no conflicts of interest regarding the publication of this paper.

\section{Acknowledgments}

The authors are very thankful to the Sichuan Agricultural University for providing the apparatus and chemicals used.

\section{References}

[1] B. E. Bundesgesundheitsamt, "Cancer causing effects of formaldehyde mutagens with a reference value of $0.1 \mathrm{ppm}$ for indoor air is not necessary," Bundesgesundheitsblatt Gesundheitsforschung Gesundheitsschutz, vol. 49, no. 11, article 1169, 2006.

[2] T. Salthammer, "Formaldehyde in the ambient atmosphere: from an indoor pollutant to an outdoor pollutant?" Angewandte Chemie International Edition, vol. 52, no. 12, pp. 3320-3327, 2013.

[3] C. Bosetti, J. K. McLaughlin, R. E. Tarone, E. Pira, and C. La Vecchia, "Formaldehyde and cancer risk: a quantitative review of cohort studies through 2006," Annals of Oncology, vol. 19, no. 1, pp. 29-43, 2008. 
[4] G. Y. Li, H. Y. Lee, H. S. Shin, H. Y. Kim, C. H. Lim, and B. H. Lee, "Identification of gene markers for formaldehyde exposure in humans," Environmental Health Perspectives, vol. 115, no. 115, pp. 1460-1466, 2007.

[5] T. Salthammer, S. Mentese, and R. Marutzky, "Formaldehyde in the indoor environment," Chemical Reviews, vol. 110, no. 4, pp. 2536-2572, 2010.

[6] J. S. Pierce, A. Abelmann, J. T. Lotter et al., "An assessment of formaldehyde emissions from laminate flooring manufactured in China," Regulatory Toxicology \& Pharmacology, vol. 81, pp. 20-32, 2016.

[7] I. R. Lucas, P. Kowalski, D. B. Callahan et al., "Formaldehyde levels in traditional and portable classrooms: a pilot investigation," Journal of Environmental Health, vol. 78, no. 7, pp. 8-14, 2016.

[8] T. Schupp, H. M. Bolt, and J. G. Hengstler, "Maximum exposure levels for xylene, formaldehyde and acetaldehyde in cars," Toxicology, vol. 206, no. 3, pp. 461-470, 2005.

[9] Y. Zhao, D. Guo, Z. Huang, W. Chang, X. Qi, and Z. Li, "Proficiency testing for determination of formaldehyde in leather in China," TrAC-Trends in Analytical Chemistry, vol. 82, pp. 279$285,2016$.

[10] A. Lino-dos-Santos-Franco, M. Correa-Costa, A. C. C. Dos Santos Durão et al., "Formaldehyde induces lung inflammation by an oxidant and antioxidant enzymes mediated mechanism in the lung tissue," Toxicology Letters, vol. 207, no. 3, pp. 278-285, 2011.

[11] A. J. Kleinnijenhuis, Y. C. M. Staal, E. Duistermaat, R. Engel, and R. A. Woutersen, "The determination of exogenous formaldehyde in blood of rats during and after inhalation exposure," Food and Chemical Toxicology, vol. 52, no. 2, pp. 105-112, 2013.

[12] P. E. Kastner, A. Casset, and F. Pons, "Formaldehyde interferes with airway epithelium integrity and functions in a dose- and time-dependent manner," Toxicology Letters, vol. 200, no. 1-2, pp. 109-116, 2011.

[13] X. Ye, Z. Ji, C. Wei et al., "Inhaled formaldehyde induces DNA-protein crosslinks and oxidative stress in bone marrow and other distant organs of exposed mice," Environmental \& Molecular Mutagenesis, vol. 54, no. 9, pp. 705-718, 2013.

[14] Y. Zhang, X. Liu, C. Mchale et al., "Bone marrow injury induced via oxidative stress in mice by inhalation exposure to formaldehyde," PLoS ONE, vol. 8, no. 9, pp. 274-274, 2012.

[15] D. R. D. Andrade Júnior, R. B. D. Souza, S. A. D. Santos et al., "Oxygen free radicals and pulmonary disease," Jornal Brasileiro De Pneumologia, vol. 311, no. 1, pp. 60-68, 2005.

[16] B. S. Ibrahim, É. D. Barioni, C. Heluany et al., "Beneficial effects of vitamin $C$ treatment on pregnant rats exposed to formaldehyde: reversal of immunosuppression in the offspring," Toxicology and Applied Pharmacology, vol. 300, pp. 77-81, 2016.

[17] L. F. Lima, G. L. Murta, A. C. Bandeira et al., "Short-term exposure to formaldehyde promotes oxidative damage and inflammation in the trachea and diaphragm muscle of adult rats," Annals of Anatomy: Official Organ of the Anatomische Gesellschaft, vol. 202, pp. 45-51, 2015.

[18] H. Wen, L. Yuan, C. Wei et al., "Effects of combined exposure to formaldehyde and benzene on immune cells in the blood and spleen in Balb/c mice," Environmental Toxicology and Pharmacology, vol. 45, pp. 265-273, 2016.

[19] S. Neuss, K. Holzmann, and G. Speit, "Gene expression changes in primary human nasal epithelial cells exposed to formaldehyde in vitro," Toxicology Letters, vol. 198, no. 2, pp. 289-295, 2010 .
[20] Golalipour, M. J. Azarhoush, R. Ghafari et al., "Can formaldehyde exposure induce histopathologic and morphometric changes on rat kidney?" International Journal of Morphology, vol. 27, pp. 1195-1200, 2009.

[21] M. Gulec, A. Gurel, and F. Armutcu, "Vitamin E protects against oxidative damage caused by formaldehyde in the liver and plasma of rats," Molecular and Cellular Biochemistry, vol. 290, no. 1-2, pp. 61-67, 2006.

[22] E. Nasiri, S. Naserirad, A. P. Lashgari et al., "Hepatoprotective effect of Acantholimon bracteatum (Girard) Boiss. On formaldehyde-induced liver injury in adult male mice," Research Journal of Pharmacognosy, vol. 3, no. 3, pp. 55-61, 2016.

[23] E. Bakar, E. Ulucam, and A. Cerkezkayabekir, "Investigation of the protective effects of proanthocyanidin and vitamin E against the toxic effect caused by formaldehyde on the liver tissue," Environmental Toxicology, vol. 30, no. 12, pp. 1406-1415, 2015.

[24] A. K. Daly, "Pharmacogenetics of the cytochromes P450," Current Topics in Medicinal Chemistry, vol. 4, no. 16, pp. 1733-1744, 2004.

[25] D. F. V. Lewis, "P450 structures and oxidative metabolism of xenobiotics," Pharmacogenomics, vol. 4, no. 4, pp. 387-395, 2003.

[26] S.-F. Zhou, J.-P. Liu, and B. Chowbay, "Polymorphism of human cytochrome P450 enzymes and its clinical impact," Drug Metabolism Reviews, vol. 41, no. 2, pp. 89-295, 2009.

[27] R. H. Elbekai and A. O. S. ElKadi, "The role of oxidative stress in the modulation of aryl hydrocarbon receptor-regulated genes by $\mathrm{As}^{3+}, \mathrm{Cd}^{2+}$, and $\mathrm{Cr}^{6+}$, , Free Radical Biology and Medicine, vol. 39, no. 11, pp. 1499-1511, 2005.

[28] A. O. S. Elkadi, A. M. Bleau, I. Dumont et al., "Role of reactive oxygen intermediates in the decrease of hepatic cytochrome P450 activity by serum of humans and rabbits with an acute inflammatory reaction," Drug Metabolism \& Disposition the Biological Fate of Chemicals, vol. 28, no. 9, pp. 1112-1120, 2000.

[29] S. Fowler, D. K.-L. Xing, B. Bolgiano, C.-T. Yuen, and M. J. Corbel, "Modifications of the catalytic and binding subunits of pertussis toxin by formaldehyde: effects on toxicity and immunogenicity," Vaccine, vol. 21, no. 19-20, pp. 2329-2337, 2003.

[30] R. J. Mitkus, M. A. Hess, and S. L. Schwartz, "Pharmacokinetic modeling as an approach to assessing the safety of residual formaldehyde in infant vaccines," Vaccine, vol. 31, no. 25, pp. 2738-2743, 2013.

[31] A. K. Panda, M. R. Reddy, S. V. R. Rao et al., "Production performances, serum/yolk cholesterol and immune competence of White Leghorn layers as influenced by dietary supplementation of probiotic," Tropical Animal Health \& Production, vol. 35, no. 1, pp. 85-94, 2003.

[32] R. M. Carlson, M. C. Smith, and S. T. Nedorost, "Diagnosis and treatment of dermatitis due to formaldehyde resins in clothing," Dermatitis, vol. 15, no. 4, pp. 169-175, 2004.

[33] K. Strong, C. Mathers, S. Leeder, and R. Beaglehole, "Preventing chronic diseases: how many lives can we save?" The Lancet, vol. 366, no. 9496, pp. 1578-1582, 2005.

[34] Z. Meng, B. Zhang, J. Bai, H. Geng, and C. Liu, "Oxidative damage of sulfur dioxide inhalation on stomachs and intestines of mice," Inhalation Toxicology, vol. 15, no. 4, pp. 397-410, 2003.

[35] Z. Meng, G. Qin, and B. Zhang, "DNA damage in mice treated with sulfur dioxide by inhalation," Environmental and Molecular Mutagenesis, vol. 46, no. 3, pp. 150-155, 2005. 
[36] Z. Meng and B. Zhang, "Oxidative damage of sulfur dioxide inhalation on brains and livers of mice," Environmental Toxicology and Pharmacology, vol. 13, no. 1, pp. 1-8, 2003.

[37] Z. Meng, "Oxidative damage of sulfur dioxide on various organs of mice: sulfur dioxide is a systemic oxidative damage agent," Inhalation Toxicology, vol. 15, no. 2, pp. 181-195, 2003.

[38] G. H. Qin, "Effects of sulfur dioxide on mRNA expression and activities of hepatic and pulmonary cytochrome P4502B1 and $2 \mathrm{E} 1$ in rats," Journal of Hygiene Research, vol. 35, no. 5, pp. 554$556,2006$.

[39] G. Qin and Z. Meng, "Effect of sulfur dioxide inhalation on CYP1A1 and CYP1A2 in rat liver and lung," Toxicology Letters, vol. 160, no. 1, pp. 34-42, 2005.

[40] M. A. Eghbal, P. S. Pennefather, and P. J. O’Brien, “ $\mathrm{H}_{2} S$ cytotoxicity mechanism involves reactive oxygen species formation and mitochondrial depolarisation," Toxicology, vol. 203, no. 1-3, pp. 69-76, 2004.

[41] X. Wang, M. Chen, X. Chen et al., "The effects of acute hydrogen sulfide poisoning on cytochrome $\mathrm{P} 450$ isoforms activity in rats," BioMed Research International, vol. 2014, Article ID 209393, 8 pages, 2014.

[42] A. Kakehashi, A. Hagiwara, N. Imai et al., "Mode of action of ethyl tertiary-butyl ether hepatotumorigenicity in the rat: Evidence for a role of oxidative stress via activation of CAR, PXR and PPAR signaling pathways," Toxicology and Applied Pharmacology, vol. 273, no. 2, pp. 390-400, 2013.

[43] T. E. Morgan, C. Lee, and B. A. Nyagode, "Regulation of Drug Metabolizing Enzymes and Transporters in Infection, Inflammation, and Cancer," in Encyclopedia of Drug Metabolism and Interactions, pp. 123-149, John Wiley \& Sons, Inc, 2008. 

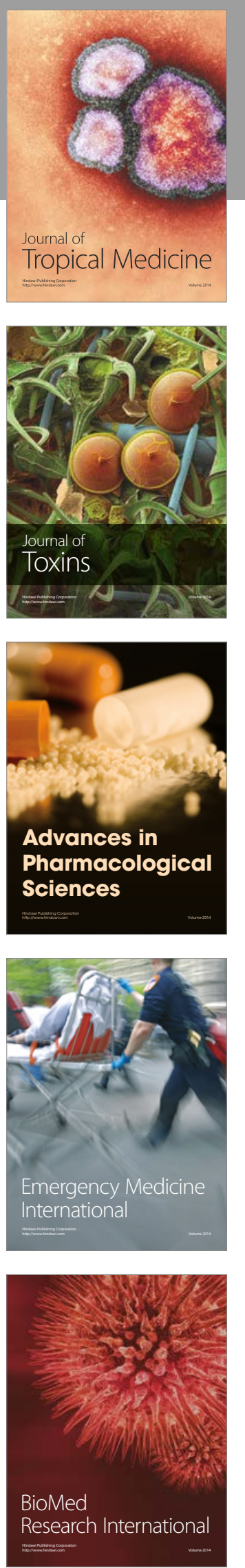
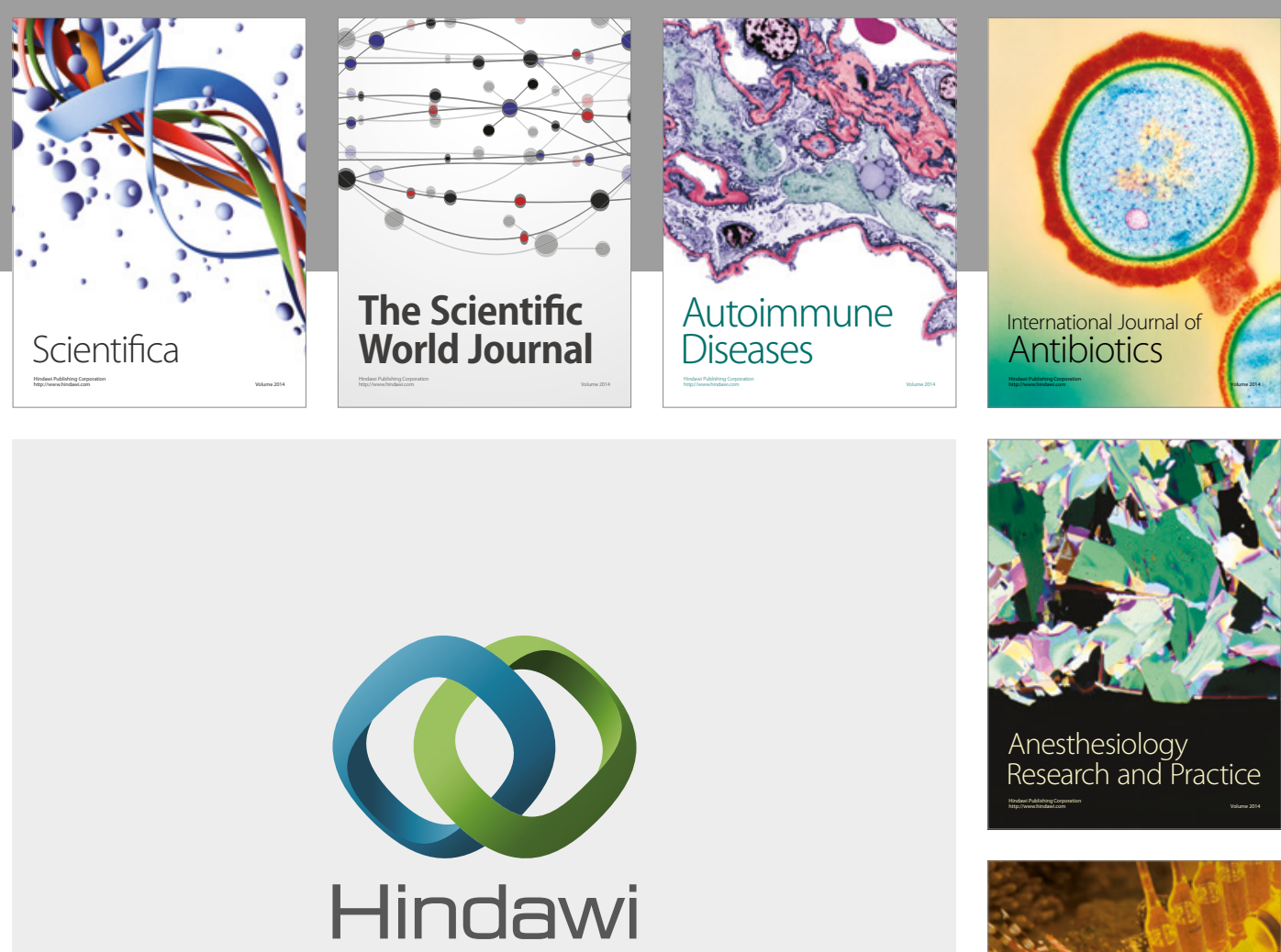

Submit your manuscripts at

https://www.hindawi.com
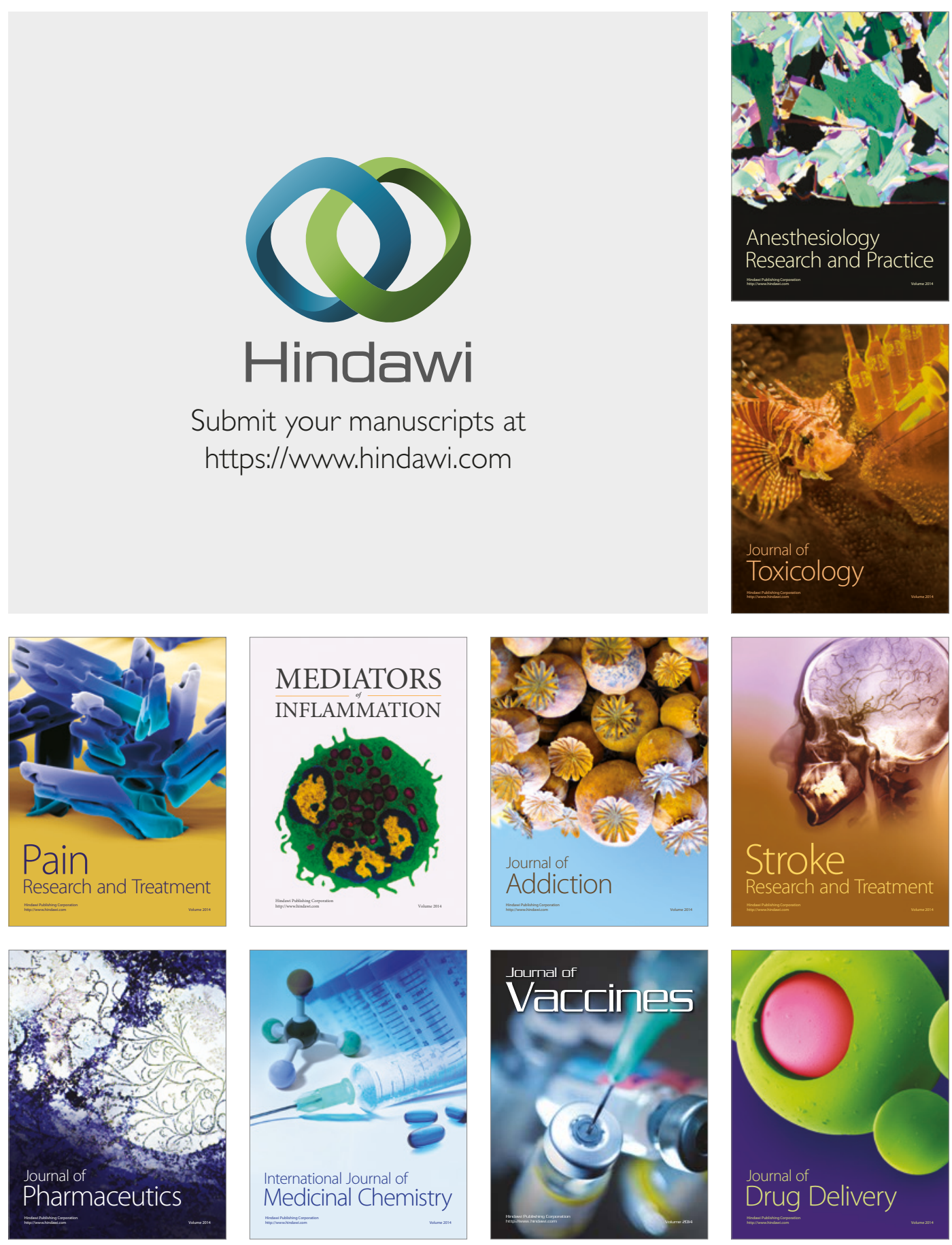